2016-12-01

\title{
Learning to mock - Challenging the teaching establishment
}

Gabriel, N

http://hdl.handle.net/10026.1/8232

10.1177/1745499916679559

Research in Comparative and International Education

All content in PEARL is protected by copyright law. Author manuscripts are made available in accordance with publisher policies. Please cite only the published version using the details provided on the item record or document. In the absence of an open licence (e.g. Creative Commons), permissions for further reuse of content should be sought from the publisher or author. 


\title{
Learning to mock - Challenging the teaching establishment
}

Research in Comparative \& International Education 2016, Vol. II (4) 369-379 (C) The Author(s) 2016 Reprints and permissions: sagepub.co.uk/journalsPermissions.nav DOI: 10.1 177/17454999/6679559 rci.sagepub.com

@SAGE

\section{Norman Gabriel}

Plymouth Institute of Education, Plymouth University, UK

\begin{abstract}
There have been very few studies that apply the work of Mikhail Bakhtin and Norbert Elias to understand the underlying learning processes of young children. This article will explore the methodological similarities between Bakhtin's ideas about the carnivalesque and Norbert Elias's theory of established-outsider relations to explain how young children can undermine the authoritative discourses of teachers in preschool classrooms. It will focus on the playful mockery that young children display within their peer-groups to challenge teaching authority. I will argue that many of the humorous events produced by young children should be viewed as an attempt to violate their teachers' expectations. Drawing attention to the utility of using humour as a special type of qualitative research tool illuminates the different ways that young children in different cultures can resist adult authority.
\end{abstract}

\section{Keywords}

Norbert Elias, established-outsider-relations, Mikhail Bakhtin, carnivalesque, young children's humour, playful mockery, peer-groups, grotesque realism, power-balances

\section{Introduction}

A good starting point to explain some of the tensions in conducting qualitative research in education is to consider the distinction between 'etic' and 'emic' which arose in anthropology from the linguistic terms 'phonemic' and 'phonetic'. An 'emic' point of view seeks to present how 'native' members of a social group perceive and categorise their world, the meanings it has for them, their feelings about it and their own rules of behaviour. Ethnographers try to interpret events from the perspective of their participants rather than from their own point of view. An 'etic' account is written from the point of view of the social scientist, recognising that there is much that members of a culture may not be able to understand in the 'scientific' description of themselves. However, such a task is made even more complex in cross-cultural studies that often involve participants from very different backgrounds, where the researcher cannot be an 'insider' to all.

Bourdieu (1977) argued that one of the most important problems in ethnographic research is the extent to which it puts a premium on natives' discursive explanations of their actions. Because the

\section{Corresponding author:}

Norman Gabriel, Plymouth Institute of Education, Plymouth University, Drake Circus, Plymouth, PL4 8AA, UK.

Email: norman.r.gabriel@plymouth.ac.uk 
anthropologist is an outsider and starts out ignorant, natives must explain things to him or her. But it would be a mistake to accept such explanations as simple truths, because they are precisely the limited form of knowledge that can be offered to one who has not mastered the practical skills of living fully inside the culture:

The anthropologist's particular relation to the object of his study contains the makings of a theoretical distortion in as much as his situation as an observer, excluded from the real play of social activities by the fact that he has no place (except by choice or by way of a game) in the system observed and has no need to make a place for himself there, inclines him to a hermeneutic representation of practices, leading him to reduce all social relations to communicative relations and, more precisely, to decoding operations.

(Bourdieu, 1977:1)

Significantly, Bourdieu argues that the insider-outsider debate may be misleading - the relevant issue is whether knowledge is being produced scientifically, which involves epistemic reflexivity. The aim of reflexivity is to produce more secure knowledge; this involves the rejection of the phenomenological stance through active distancing from the presuppositions associated with the subjective experiences of those being researched. For comparative educational research to be conducted, researchers should therefore move beyond the explicit cognitive rules or statements that different participants offer about their social relationships.

Bourdieu wanted to grasp the practical strategies people employed, their relationship to the explanations they gave (to themselves as well as to others), and the ways in which people's strategic pursuit of their own ends tended to reproduce objective patterns which they did not choose and of which they might even be unaware. In this article, I will apply this theoretical insight of Bourdieu to investigate 'insider-outsider' relations in preschool classrooms, explaining how young children can undermine the authoritative discourses of teachers through humour of which they are not always aware.

Bourdieu's controlled scientific reflexivity is very similar to Norbert Elias's (2007) explanation of the role of the involvement-detachment balance in developing scientific research. Although Elias did not explicitly address educational practice or the role of education in society, he was deeply interested in the development of the social learning processes of young children and adults. Elias's argument is that for research to become more firmly established, the practitioners of an emerging science should gradually develop a strong, emotional commitment to the science concerned. For Elias, researchers execute a 'detour via detachment', whereby they suspend moral and political convictions but return to them in a new form after theoreticalempirical inquiry. After a reframing of the problem through comparative research, one returns to the issue better armed for seeing the partiality of the original formulation as it becomes absorbed into a wider explanatory framework, one that is based in the universal features of human society:

For it to become anything, an empirically based conception of the similarities between all possible societies is essential, to provide a frame of reference within which particular investigations may be carried out.

(Elias, 2012a: 99).

Through the examples I draw upon from different countries, this article will argue that humour can be used as a special type of qualitative research tool to gain insight into the similar ways that young children in different cultures challenge and resist adult authority. 


\section{Established-outsider relations}

Elias and Scotson's theory of established-outsider relations was based on a study in 1958-1961 of a community on the outskirts of Leicester that was then ethnically homogeneous, white and working-class. For Elias, it was the power-ratio and relational access to community resources between the established and outsiders that explained the relationship of domination. As he and Scotson noted: 'the ability of one group to pin a badge of human inferiority on another group and make it stick was a function of a specific figuration which the two groups formed with each other' (Elias and Scotson, 2008: 6) When established groups feel exposed to an attack against their monopolised power resources, they use stigmatisation and exclusion as weapons to maintain their distinct identity, assert their superiority and keep outsiders in their place.

Through his concept of the 'dialogic self' Bakhtin's work (1986) can also be used to explain how established-outsider relations are processes. According to Bakhtin, language is inherently dialogical as individual consciousness lies on the borderline between the self and another. The word in language is half someone else's. It becomes 'one's own' only when appropriated with intention. Crucially, each word contains, within itself, diverse, discriminating and often contradictory components. A dialogue thus becomes a model which can be used to explain the emergence and development of group processes:

In the realm of culture, outsideness is a most powerful factor in understanding ... A meaning only reveals its depth once it has encountered another foreign meaning ... We raise new questions for a foreign culture, ones that it did not raise for itself; we seek answers to our questions in it, the foreign culture responds to us by revealing to us its new aspects and new semantic depths.

(Bakhtin, 1986: 7)

For Bakhtin, 'outsideness' is an important pre-requisite for creatively understanding another person or another culture. As an example of this dialogic process, carnivalesque is a type of humour that resides underneath solemnity and emerges out of it. Bakhtin's (1984a) work on carnival is found in his seminal book on the subject, Rabelais and His World. Here, Bakhtin captured what was an unappreciated aspect of Medieval and Renaissance festivals, namely, a spirit of change and renewal. Carnival turns the social order topsy-turvy - it is a form of rejuvenation achieved through the playful mocking of the hierarchical order by individuals who find themselves oppressed by it.

During carnivals and similar festive periods, former ranks and hierarchies disappeared. All participants to the carnival were considered equal and free, and familiar contacts were allowed between different social classes and positions. These rituals stressed the all-joyous characteristics of life and opened the way for playful undefined relationships. Furthermore, the festivals allowed the articulation of the idiomatic 'world turned upside down', a funny and subversive way to play with established rules and hierarchies.

In this article, I will argue that Bakhtin's (1984a) ideas about the relationship between carnival, authority and laughter can be integrated with Elias's view of the established and outsiders to explain how one 'outsider' group, young children, can challenge the hierarchical order of the established group, adults (early years' teachers and practitioners). Although Norbert Elias's theory of established-outsider relations has mainly been applied to changing power-balances between classes, ethnic groups, colonisers and colonised, and men and women, it can also be used to explain a distinctive aspect of young children's processes of learning, the way in which they can undermine and transgress the authoritative discourses of adults. I will focus on the playful opportunities that young children have for challenging teacher authority by exploring their peer cultures where they 
can take charge and control of themselves. It will draw on examples from different countries to illustrate the different forms of playful mockery that young children use to resist adult authority and challenge the 'adult-shame frontier':

Children necessarily encroach again and again on the adult threshold of repugnance, and - since they are not yet adapted - they infringe the taboos of society, cross the adult shame frontier, and penetrate emotional danger zones which the adults themselves can only control with difficulty. In this situation the adults do not explain the demands they make on behaviour. They are unable to do so adequately. They are so conditioned that they conform to the social standard more or less automatically.

(Elias, 2012b: 164).

\section{Young children's play}

Young children's play has usually been dismissed by adults as harmless high-jinks, games in which everyone runs around, giggles, squeals or shouts, arguing over rules or their application. In Western societies, early study of the influence of play on development, linked with the emergence and dissemination of constructivist theories of learning (Piaget, 1951; Vygotsky, 1978) led to enthusiasm for providing 'playful learning' in both family and preschool settings. However, the resulting 'play pedagogies' (Wood, 2009) were viewed as both Eurocentric for children in the Majority World where, it was assumed, childhood was a time for work or study rather than for play. These traditional conceptions of play reflected the perspectives of Western scholars who have studied the interactions of middle-class European or Euro-American children (Trawick-Smith, 2010). Research on play has been too narrow in scope, focusing only on childhood pastimes that are observed within Western societies while overlooking or undervaluing many significant play forms that are common in non-Western cultures.

Cross-cultural studies have helped to address this Eurocentric approach: Gaskin et al. (2006) have argued that when children's play is compared across cultures that differ on the amount of adult tolerance for and involvement in play, it can provide a more accurate understanding of cultural variation. They have drawn on case studies to support a classification of cultural attitudes to play as 'cultivating' (Euro-American and Taiwanese families), where adults spend a great deal of resources supporting and extending it; when play is not seen by parents as intrinsically valuable to children, it can be considered as 'accepting' or taken for granted (the Kpelle community in Liberia). And where it is 'curtailed', children spend a lot of their time working and observing others - in a Mayan community in Mexico, there is little adult supervision, mediation, encouragement or participation. In Africa, Mtonga (2012) compiled the texts of indigenous Chewa and Tumbuka children's songs and observed games in the 1980s in rural and urban areas of Zambia. His analysis of guessing games and riddle contests emphasised how these games encouraged children to think about their own and others' activities - of particular significance were the language games which demonstrated 'playful and skilful manipulation of certain word-sounds in order to distort meaning, create new concepts, or paint a satirical caricature'.

However, studies of riddles in African contexts have tended to emphasise their role in instilling cultural values (see Kyoore 2010; Noss 2006). They discuss the use by adults of riddles - and, in a similar way, other forms of African folklore - as a means of educating and disciplining children. The social and educational meaning of riddling from the children's perspective and the way these meanings are interpreted in the children's peer culture, have to a limited extent been included in the studies of children's folklore in African contexts. The limitations of the study of the African oral tradition are now being recognised. Jirata (2012) has explored how riddling, a popular form of 
children's folk culture among the Guji people in Ethiopia, differentiates children's culture from the adult cultural world. She has shown that children can create and share their own cultural practices through which they resist adult imposition. Another good example of this development is the work of Nicolas Argenti (2010), who approaches folktales as child-centred verbal play through which children express their lived experience; in the Cameroon grassfields, children - usually so respectful in the presence of elders - revel in the violence and scatological obscenity with which the folktales abound.

In a Western context, children's folklore has been an object of study for over 150 years, with researchers recognising the importance of playground games, and clapping and skipping songs. The work of Alice Gomme in 1894 and 1898, which led to the publication of the book The Traditional Games of England, Scotland and Ireland (Gomme, 1964), 'did much to establish the study of children's folklore as a valid field of investigation in its own right' (Bishop and Curtis, 2001: 5). Important collections have preserved and protected traditional rhymes and games (Halliwell, 1849), emphasising the inventiveness and richness of an oral tradition sustained by children alone (Opie and Opie, 1959, 1969, 1985).

These studies have documented thousands of rhymes, clapping rhymes, skipping games, language play, imaginative play and games with rules that are usually referred to as 'childlore'. They were based on information contributed by 20,000 children from schools all over Britain, in response to three surveys, supplemented by the Opies' own in-depth observations and sound recordings. The collection covers a wide range of play and traditions in a variety of outdoor environments - including linguistic items, games, rhymes, songs, customs, rites of passage and beliefs - and provides ethnographic detail on transmission, performance and recreation. Studies have noted the interplay between historical continuities and the continual change through which playground lore responds to contemporary cultural preoccupations. Kathryn Marsh (2008), for example, offers a detailed account of the way in which the media informs the lore of the playground. She emphasises the way in which the 'parody songs and related parodic movements aptly represent children's subversion of adult culture in their play. The creation of parallel texts allows children to ridicule adult concerns' (Marsh, 2008: 171).

Young children's playground games have been investigated from various perspectives: as forms of identity and socialisation (James, 1993); as linguistic patterns (Crystal, 1998); as informal literacies (Grugeon, 1988); as musical and compositional practice (Marsh, 2008) and as forms of creative learning (Bishop and Curtis, 2001). But they often gloss over their scatological, obscene and anti-authoritarian nature (Bauman, 1982). According to Bakhtin (1984a), a key aspect of carnival is grotesque realism. Degradation is the dominant element of grotesque realism, which is marked by a lowering of abstract, idealised principles (which are in the head). Much of what constitutes such degradation is associated with the body: drinking and eating, for example. However, grotesque realism usually exalts the lower stratum of the body 'because it is the fruitful earth and the womb. It is always conceiving' (Bakhtin, 1984a: 21), generating the spirit of change and renewal. This exaltation of bodily functions was in direct contrast to the medieval Church, which exalted the rationality of the head and depicted the body as a site of defilement. In addition to corporal references, grotesque realism consists of discursive features, notably curses, oaths, slang, tricks, jokes, and scatological and other forms of folk humour as part of an overall comic ridicule and profanation of authority.

\section{Humour in early childhood education}

Despite a considerable volume of psychological-based research investigating the pedagogical prominence of young children's humour (see, for example, Loizou, 2007; Raskin, 2009), it has not 
enjoyed the attention it warrants within educational research. Of the wide range of studies of humour in education over the last four decades, few have explored humour within early childhood education, focusing instead on school-aged children (Banas et al., 2011). Nevertheless, a small number of studies have explored the social aspect of engagement as a key to understanding young children's humour in early childhood education. Loizou's investigation of 18- and 21-month-old children provides several examples of their deliberate employment of mismatching in order to generate a reaction from others. Such incongruity was evident in the violation of rules, misnaming of items, misuse of materials and even, in the case of the 21-month-old, the telling of 'knockknock' jokes. Much of this humour was directed towards the teacher and sought a reaction in response, even if it was a negative one. Loizou (2007: 24) concludes by suggesting that humour 'is a social and playful activity that can be a catalyst for the development of social knowledge and lead to the understanding of one's self as a social agent, early on'.

In order to make comparisons of the significance of humour within early childhood education across different countries, we can look at the 28 OECD countries in UNICEF's Child Wellbeing in Rich Countries Report (UNICEF, 2013), where 18 countries have national guidance for early childhood education. Of those 18, only 3 contain a reference to humour: the UK, Norway and Ireland. None of the references is detailed, with the most attention to humour appearing in the Norwegian 'Barnhage' guidelines (World Education Service, 2014) where it is mentioned in relation to play, creativity and environment. The UK Early Years Foundation Stage Non Statutory Guidance includes the word 'humour' only once in the Communication and Language Development section, stipulating it is desirable that a child between 40 and 60 months, 'understands humour, e.g. nonsense rhymes and jokes'.

Such cross-cultural comparisons strongly suggest that humour is undervalued as an educational tool in early childhood. However, there are notable exceptions - recent New Zealand assessment discourse based on Kaupapa Maori ideology highlights the significance of adults' recognition and engagement with young children's humour (Ministry of Education, 2009). Drawing on the metaphor of Maui-tika-tika-a-Tauranga (a character from a popular legend), teachers are encouraged to value humour as a disposition which privileges the notion of whakatoi/whakataka - described by Rameka (2010: 35) as 'cheekiness, spiritedness, displaying and enjoying humour, having fun'.

One important explanation for practitioners not 'seeing' or valuing the pedagogic aspects of humorous play is because it enables young children to explore the power boundaries that lie beyond the gaze of adults. Young children exercise an element of control over their underground world by finding opportunities to engage in humour that explores forbidden territory. I now want to focus on the subversive aspects of young children's humour, drawing on some examples to illustrate how they enable young children to explore their environment. They are often scatological or sexual, and publishers in the past have often been reluctant to publish them because of the fear of shocking adults. Adults cannot bear too much reality, but 'Defecation, urination, nudity, the private parts, the sex organs, and the sex act, which, in a civilized society, are kept private, have a fearful fascination for children' (Opie, 1993: 15).

\section{Trouble and taboo}

Cohen (2011) offers an important example of how young children's play sometimes includes imitative elements that border on caricature, satire or the parody of adult roles and behaviours. She uses examples from her study of culturally diverse three- and four-year-olds in the US to identify three main similarities between Bakhtin's ideas about carnival in the Middle Ages and young children's pretence in preschool classrooms. Bakhtin argues that carnival belongs fully to all people and occurs in the public square. In a way, very similar to the public square, the dramatic-play area 
occupies a separate location in the early childhood classroom where all children can assume the roles of different characters. It typically contains a kitchen area, a table and chairs, a doll's high chair, a doll bed and dolls representing many cultures. The furniture usually separates the area from the larger classroom. All children in a preschool programme can participate in dramatic play, which is self-motivated and self-directed, and the area becomes the space where players create a different world within the official world of preschool.

A second important similarity of carnival and pretend role play resides in the dressing up and masquerading common in both rituals. In the public square, people used masks and marionettes to take on new identities and overcome fear - to free themselves from the pressures of those with power. Young children use dramatic play in a similar way. They wear hats, scarves and jackets as they take on the roles of mother, father, baby and community workers and use realistic props, such as telephones, toy food, dishes and stuffed animals as they pretend to eat dinner, celebrate a birthday or work in an office. Through such pretence with clothes and props, young children work out the tensions and paradoxes of the uncertainties of the official adult world that surrounds them (Corsaro, 2005), adapting their voices or their ways of speaking to suit particular roles. Bakhtin (1984b: 185) defines this interaction as 'double-voiced speech', or discourse that is 'directed toward someone else's speech'.

In double-voiced speech, a speaker makes use of another's discourse such that two intentions or speech centres are present in the discourse. Double-voiced discourse occurs when diverse voices interact and struggle to assimilate authoritative discourse (official discourse) and internally persuasive discourse (unofficial discourse). Authoritative discourse is fused with authority and power, located in a distanced zone and connected with a prior discourse higher in the hierarchy. In contrast to authoritative discourse, unofficial or internally persuasive discourse is more flexible and dynamic. With internally persuasive discourse, we appropriate the words of others, redefine them and establish our own voice.

A third similarity between carnival and pretend role play resides in the planning of playful events. Carnival practices, such as underwear becoming outerwear, clothes worn inside out, nose picking and displaying backsides were common during festivals. Participants were able to communicate openly and in ways that exercised freedom from societal constraints through laughter, grotesque acts and profanities. For Bakhtin 'the unofficial carnival is people's second life, organized on the basis of laughter' (Bakhtin, 1984a: 8), which has the 'power of making an object come up close, of drawing it into a zone of crude contact where one can finger it familiarly on all sides, turn it upside down, inside out, and peer at it from above' (Bakhtin, 1981: 23). Carnival is a way of breaking down barriers, of overcoming power inequalities through the playful mockery of hierarchical order by individuals oppressed by it. Similar to the carnival, young children are placed in an official hierarchy that subjects them to the demands of parents and teachers - they escape official channels, resist authority and generate disorder to gain control of their lives (Corsaro, 2005).

Tallant (2015) provides another illuminating example of carnivalesque behaviour taking place during her ethnographic fieldwork. It involved two children, Sian and Simon, aged three and four. During a conversation with Simon and Sian while playing with porridge oats, the children, who had previously asked her for permission as if she were a practitioner, appeared to accept her as an equal in the humorous encounter. Their conversation began with a discussion about dinosaurs and their habitat. It was suggested that some lived in nests and the conversation moved on to who or what else can live in a nest. When it was suggested that she might live in a bird's nest, the conversation took on a carnivalesque spirit (Tallant: 2015: 257):

Simon: (laughing)... you couldn't go in there with that bird poo. But you could clean the bird poo up and put it in a bucket. 
Laura: Oh, and where would I put the bird poo then?

Sian: (shouts) IN THE DINOSAUR'S MOUTH (laughs).

Laura: (in an exaggerated tone) In the dinosaur's mouth (laughs)?

Simon: No, in the sink (laughs).

Laura: In the sink (smiles). What would happen to the sink if I put all of that bird poo down there?

Simon: (smiling) It would be smelly (laughs). You could put it in the bath (laughs).

Laura: We could put it in the bath $-\mathrm{hmmm}$ (smiles).

Sian: Just do it (smiles).

Laura: A bath is for getting us clean. If we put bird poo in it, do you think a bath would get us clean?

Simon: You can put soap in bird poo (smiles).

Laura: Hmmm - or perhaps it should just stay outside?

Sian: Yeah, I think so.

Laura: Do you think so?

Simon: Yeah, so the birds can eat it (laughs). Sian laughs, too.

Humour is an important aspect here because it allows young children to challenge adult power, to explore taboo topics such as sex or toilets and to experiment with dazzling displays of verbal dexterity. Tallant (2015) argues that in engaging with grotesque realism, young children feel empowered in an environment where they experience very little power. They can debase adult authority by using imagery that dominant cultural discourses claim as inappropriate, relishing the power they have over their own bodies. This may be a particularly enjoyable experience because children of three and four may have only recently become toilet-trained and gained control over their bladders and bowels. Power is therefore an integral aspect of humour that young children use to negotiate their social surroundings (Loizou, 2007).

Loizou (2005) explored how six one- to two-year-old children in group child care demonstrated their ability to appreciate and produce humour. She defines humour as the ability to empower oneself by playfully violating or appreciating the violation of someone's expectations and responding through smiles or laughter. Many of the humorous events were intentionally produced by young children as an attempt to violate their peers' or caregivers' expectations in order to make themselves feel superior to their caregivers. For example, instead of using the sponge to clean their space, some children would put it in their mouth, look up at their caregiver and smile, knowing and understanding their action and implications. This was a favourite activity, and once one child started, the rest followed. They produced and sometimes appreciated similar events by watching their peers put the sponge in their mouths.

Nevertheless, there are a number of potential barriers to the recognition of young children's carnivalesque humour as pedagogically valuable. White (2014) suggests a possible obstacle is teachers' accountability which may prevent them from responding to this form of humour. The 'fear of dissolution of boundaries' (Grace and Tobin, 1997: 165) between young children and practitioners may mean that many early childhood teachers have an aversion to popular culture infiltrating the nursery environment, considering its presence as a possible 'threat ... to teacher supremacy' (Grace and Tobin, 1997: 165). A preoccupation with the 'serious' and contained aspects of the curriculum in early childhood education is reflected in the idea that, 'laughter and play do not allow themselves to be controlled and may therefore not be understood by reason that aims to find causes and seek defined goals' (Øksnes, 2008: 162). 
In early childhood education where there is more emphasis on play, White (2014) argues that the role of the teachers in carnivalesque lies in their ability to recognise its potential to act as a counterpoint for humour through juxtaposition and incongruity. It is to recognise the sophisticated nature of the dialogic communication that young children offer through every act, not merely those that can be aligned to the official discourses of learning. The teacher's engagement with very young children's carnivalesque laughter is therefore a complex exchange that can never lay claim to the fullest experience of the young child or peer-group.

She suggests that there are unique pedagogical challenges for teachers in positioning themselves horizontally and vertically: the former resides in recognising one's role as integral to the humour that takes place (as an authorial partner, one is willing to become the object of ridicule, who potentially becomes the butt of the joke); while the latter demands a stepping away from the role as 'expert' to one of dialogic uncertainty that recognises carnivalesque lies within the domain of the peer-group. Such a dual stance is potentially transformative if adults can recognise the capacity for carnivalesque to support young children's sense of selfhood. Embracing both these horizontal and vertical roles ensures that carnivalesque can thrive as a major way of engaging with others in order to mark out one's place. In recognising carnivalesque as the domain of the young child, the teacher can view their role as an outsider in peer-based learning: as a necessary source of authority and otherhood from the underground culture of the young child.

\section{Conclusions}

In these concluding remarks, I want to discuss some of the important methodological implications of conducting qualitative research with young children, focusing on the humorous aspects of their playful activities. I have argued that Elias and Bakhtin's theoretical perspectives can be used to understand the relational dynamics of established-outsider relations in early childhood education, highlighting the contradictory tensions in dialogical encounters in group care and education. To conduct educational research, researchers should focus on social actors' different positions, which relate to one another within fields of power. A synthesis of these two theorists' relational approaches emphasises the social interdependence between young children and adults (teachers and carers), focusing attention on the changing power balance that characterises this relationship.

Moreover, both theories provide the much needed methodological tools to investigate universal processes that not only marginalise young children as outsiders but also provide sensitising concepts that can explain challenges to the teaching establishment. I have argued that Bakhtin's concept of carnival and Elias's concept of the 'adult-shame' frontier can be used to illuminate the subversiveness of pretend play, a distinctive play which 'affords children the necessary distance or otherness from which to objectify and comment on the adult spheres of life' (Duncan and Tarulli, 2003: 283).

Through the different examples I have discussed, this article has drawn attention to the utility of using humour as a special type of qualitative research tool to gain insight into the different ways in which young children in different cultures challenge and resist adult authority. Bornstein (2006: 115) argues that 'Although human societies vary in the amount and type of such play, anthropological accounts attest that fully developed pretend play ... appears to be universal'. Humour is such a fundamental aspect of human experience and our understanding of what it is to be human, that to ignore the humorous as a rich qualitative technique for conducting comparative educational research is at the very least to reject a potentially insightful methodological approach. 


\section{Declaration of conflicting interest}

The author(s) declared no potential conflicts of interest with respect to the research, authorship, and/or publication of this article.

\section{Funding}

The author(s) received no financial support for the research, authorship, and/or publication of this article.

\section{References}

Argenti N (2010) Things that don't come by the road: Folktales, fosterage, and memories of slavery in the Cameroon grassfields. Comparative Studies in Society and History 52(2): 224-254.

Bakhtin MM (1981) The Dialogic Imagination. Austin, TX: University of Texas Press.

Bakhtin MM (1984a) Rabelais and his world. Bloomington, IN: Indiana University Press.

Bakhtin MM (1984b) Problems of Dostoevsky's Poetics. Minneapolis, MN: University of Minnesota Press.

Bakhtin MM (1986) Speech genres and other late essays. Austin, TX: University of Texas.

Banas JA, Dunbar N, Rodriguez D, et al. (2011) A review of humour in educational settings: Four decades of research. Communication Education 60(1): 115-144.

Bauman R (1982) Ethnography of children's folklore. In: Gilmore P and Glatthorn A (eds) Children In and Out of School. Washington, DC: Center for Applied Linguistics, pp.172-186.

Bishop JC and Curtis M (2001) Introduction. In Bishop JC and Curtis M (eds) Play Today in the Primary School Playground: Life, Learning and Creativity. Buckingham, UK: Open University Press, pp.1-19.

Bornstein M (2006) On the significance of social relationships in the development of children's earliest symbolic play: An ecological perspective. In: Göncü A and Gaskins S (eds) Play and Development. Evolutionary, Sociocultural and Functional perspectives. Mahwa, NJ, Lawrence Erlbaum Associates, pp.101-129.

Bourdieu P (1977) Outline of a Theory of Practice. Cambridge, UK: Cambridge University Press.

Cohen LE (2011) Bakhtin's carnival and pretend role play: A comparison of social contexts. American Journal of Play 4(2): 176-202.

Corsaro W (2005) The Sociology of Childhood, 2nd edn. Thousand Oaks, CA: Pine Forge Press.

Crystal D (1998) Language Play. London: Penguin.

Duncan RM and Tarulli D (2003) Play as the leading activity of the preschool period: Insights from Vygotsky, Leontev, and Bakhtin. Early Education and Development 14(3): 271-92.

Elias N (2007) Involvement and Detachment. The Collected Works of Norbert Elias. Vol. 8. Dublin: UCD Press.

Elias N (2012a) What is Sociology? The Collected Works of Norbert Elias. Vol. 5. Dublin: UCD Press.

Elias N (2012b) On the Process of Civilisation. The Collected Works of Norbert Elias. Vol. 3. Dublin: UCD Press.

Elias N and Scotson JL (2008) The Established and the Outsiders. The Collected Works of Norbert Elias. Vol. 4. Dublin: UCD Press.

Gaskins S, Haight W and Lancey D (2006) The cultural construction of play. In: Göncü A and Gaskins S (eds) Play and Development. Evolutionary, Sociocultural and Functional Perspectives. Mahwah, NJ: Lawrence Erlbaum Associates, pp.179-202.

Gomme AB (1964 [1984/1898]) The Traditional Games of England, Scotland and Ireland: With Tunes, Singing Rhymes, and Methods of Playing According to the Variants Extant and Recorded in Different Parts of the Kingdom. New York: Dover.

Grace DJ and Tobin J (1997) Carnival in the classroom: Elementary students making videos. In: Tobin J (ed.) Making a Place for Pleasure in Early Childhood. London: Yale University, pp.159-187.

Grugeon E (1988) Underground knowledge: What the Opies missed. English in Education 22(2): 9-17.

Halliwell JO (1849) Popular Rhymes and Nursery Tales. London: John Russell Smith.

James A (1993) Childhood Identities: Self and Social Relationships in the Experience of the Child. Edinburgh, UK: Edinburgh University Press. 
Jirata TJ (2012) Learning through play: An ethnographic study of children's riddling in Ethiopia. Africa 82(2): 272-286.

Kyoore PKS (2010) A study of riddles among the Dagara of Ghana and Burkina Faso. Journal of Dagaare Studies 7(10): 21-40.

Loizou E (2005) Infant humor: The theory of the absurd and the empowerment theory. International Journal of Early Years Education 13(1): 43-53.

Loizou E (2007) Humour as a means of regulating one's social self: Two infants with unique humorous personas. Early Childhood Development and Care 177(2): 195-205.

Marsh K (2008) The Musical Playground: Global Tradition and Change in Children's Songs and Games. Oxford, UK: Oxford University Press.

Ministry of Education (2009) Te Whatu Pokeka: Kaupapa Maori Assessment for Learning. Wellington, New Zealand: Learning Media.

Mtonga M (2012) Children's Games and Plays in Zambia. Lusaka, Zambia: University of Zambia Press.

Noss PA (2006) Gbaya riddles in changing times. Research in African Literatures 37(2): 34-42.

Øksnes M (2008) The carnival goes on and on! Children's perceptions of their leisure time and play in SFO. Leisure Studies 27(2): 149-164

Opie I (1993) The People in the Playground. Oxford, UK: Oxford University Press.

Opie I and Opie P (1959) The Lore and Language of Schoolchildren. Oxford, UK: Oxford University Press.

Opie I and Opie P (1969) Children's Games in Street and Playground: Chasing, Catching, Seeking. Vol. 1. Oxford, UK: Clarendon Press.

Opie I and Opie P (1985) The Singing Game. Oxford, UK: Oxford University Press.

Piaget J (1951) Play, Dreams and Imitation in Childhood. London: Heinemann.

Rameka L (2010) Kaupapa Maaori assessment: A journey of meaning making. Early Childhood Folio 13: $32-37$.

Raskin V (2009) (ed.) The Primer of Humor Research. Berlin: Mouton de Gruyter.

Tallant L (2015) Framing young children's humour and practitioner responses to it using a Bakhtinian carnivalesque lens. International Journal of Early Childhood 47(2): 251-266.

Trawick-Smith J (2010) Early Childhood Development: A Multicultural Perspective. Columbus, OH: Merrill.

UNICEF (2013) Child Wellbeing in Rich Countries Report. Available at: www.unicef.org.uk/Latest/ Publications/Report-Card-11-Child-well-being-inrich-countries/ (accessed 27 April 2016).

Vygotsky LS (1978) Mind in Society: The Development of Higher Psychological Processes. Cambridge, MA: Harvard University Press.

White EJ (2014) Are you 'avin a laff?: A pedagogical response to Bakhtinian carnivalesque in early childhood education. Educational Philosophy and Theory 46(8): 898-913.

Wood E (2009) Conceptualising a pedagogy of play: International perspectives from theory, policy and practice. In: Kuschner D (ed.) From Children to Red Hatters. Play and Culture Studies, vol. 8. Lanham Seabrook, MD: University Press of America, pp.166-189.

World Education Service (2014) WES Regional Education Links. Available at: www.wes.org/ewenr/researchEurope.asp?country=76\#Hungary (accessed 27 April 2016).

\section{Author biography}

Norman Gabriel is a lecturer in Early Childhood Studies in the Institute of Education at Plymouth University. Inspired by Norbert Elias, his research interests are in relational sociology and the sociology of early childhood. With Professor Stephen Mennell, he co-edited, 'Norbert Elias and figurational research: Processual thinking in sociology' (2011), a monograph for The Sociological Review series. His new book, The Sociology of Early Childhood: Critical Perspectives will be published by SAGE in March 2017. 